\title{
Frailty in patients with acute coronary syndrome: comparison between tools for comprehensive geriatric assessment and the Tilburg Frailty Indicator
}

Izabella Uchmanowicz'

Magdalena Lisiak'

Radosław Wontor ${ }^{2}$

Krystyna Łoboz-Grudzień 1,2

'Department of Clinical Nursing, Wrocław Medical University, Wrocław, Poland; ${ }^{2}$ Department of Cardiology,

T Marciniak Memorial Hospital,

Wrocław, Poland
Correspondence: Izabella Uchmanowicz Department of Clinical Nursing, Wrocław Medical University, K Bartla 5, 5I-6I6 Wrocław, Poland

Tel +48 603765770

Email izabella.uchmanowicz@am.wroc.pl
This article was published in the following Dove Press journal:

Clinical Interventions in Aging

3 March 2015

Number of times this article has been viewed

Purpose: It is a known fact that age is a strong predictor of adverse events in acute coronary syndrome (ACS). In this context, the main risk factor in elderly patients, ie, frailty syndrome, gains special importance. The availability of tools to identify frail people is relevant for both research and clinical purposes. The purpose of this study was to investigate the correlation of a scale for assessing frailty - the Tilburg Frailty Indicator (TFI) and its domains (mental and physical) - with other research tools commonly used for comprehensive geriatric assessment in patients with ACS.

Patients and methods: The study covered 135 people and was carried out in the cardiology ward at T Marciniak Lower Silesian Specialist Hospital in Wroclaw, Poland. The patients were admitted with ACS. ST segment elevation myocardial infarction and non-ST segment elevation myocardial infarction were defined by the presence of certain conditions in reference to the literature. The Polish adaptation of the TFI was used for the frailty syndrome assessment, which was compared to other single measures used in geriatric assessment: the Mini-Mental State Examination (MMSE), the Hospital Anxiety and Depression Scale (HADS), and Katz Index of Independence in Activities of Daily Living (ADLs).

Results: The mean TFI value in the studied group amounted to 7.13 \pm 2.81 (median: 7, interquartile range: 5-9, range [0, 14]). Significant correlations were demonstrated between the values of the TFI and other scales: positive for HADS $(r=0.602, P<0.001)$ and the reverse for MMSE $(r=-0.603, P<0.001)$ and IADL $(r=-0.462, P<0.001)$. Patients with a TFI score $\geq 5$ revealed considerably higher values on HADS $(P<0.001)$ and considerably lower values on the MMSE $(P<0.001)$ and IADL scales $(P=0.001)$.

Conclusion: The results for the TFI comply with the results of other scales (MMSE, HADS, ADL, IADL), which confirm the credibility of the Polish adaptation of the tool. Stronger correlations were observed for mental components and the mental scales turned out to be independently related to the TFI in a multidimensional analysis.

Keywords: frailty syndrome, acute coronary syndrome, screening tools, elderly

\section{Introduction}

Extension of life expectancy is related to a significant increase in the number of elderly people. ${ }^{1}$ It results in an increased demand for medical services and entails the need to improve quality of life and everyday functioning of the eldest citizens. ${ }^{2}$ With regard to the above, the main risk of complications in elderly people, ie, frailty syndrome (FS), gains special importance. ${ }^{2-4}$

It is considered that patients with FS require special attention. On the one hand, the risk of their disability or death is quite high, but, on the other hand, many elements 
of FS can be reversed if diagnosed appropriately. Prevention might be most beneficial for those at high risk for dependency and disability, ie, frail older people. ${ }^{3}$

Recently, the literature has emphasized the contribution of FS to acute coronary syndrome (ACS). Half of cases of ACS concern patients $\geq 75$ years old. ${ }^{5}$ It is known that age is a strong predictor of adverse events in ACS. ${ }^{6}$ The elderly population is more susceptible to hemorrhagic complications, renal failure, and incidents involving the central nervous system. Nevertheless, patients at increased risk may benefit significantly from coronary interventions. Research shows, however, that invasive therapy and cardiological treatment are rarely used in this population, and the population is also rarely qualified for clinical studies. ${ }^{7}$ Not only age but also related disease conditions (anemia, renal insufficiency, FS, disturbed cognitive functions) are the cause of adverse events after ACS. The American Heart Association Council recommends taking $\mathrm{FS}$, cognitive functions, and concomitant diseases into account while making risk assessments and selecting therapy in ACS. There is evidence that the changes influence prognosis after ACS and are of key importance for selecting therapy in patients with non-ST segment elevation myocardial infarction (NSTEMI). ${ }^{5}$

The availability of tools to identify frail people is relevant to both research and clinical purposes. In order to avoid costs and unnecessary assessments, valid and low-cost tools are needed to screen elderly people who are at particular risk of developing adverse outcomes. ${ }^{8}$ With regard to disability prevention, valid screening instruments are needed to identify frail older people.

With regard to the above, early diagnosis of FS and implementation of appropriate intervention aimed at minimizing the negative effects of the syndrome and improving the quality of life of patients suffering from the disease are extremely important. ${ }^{9}$ However, in practice, this means facing various problems related to the previously mentioned lack of coherent definition of FS or uniform diagnostic criteria for the syndrome. The clinical markers of frailty include: nutritional condition, mobility, activity, strength and endurance, cognitive functions, and mood. Nevertheless, the large number and variability of the factors determining the presence of FS justifies the creation of a simple screening tool that could be used for diagnosing the syndrome. Recent years have seen the development of various tools meeting the criteria; their value varies, though, due to the fact that none of them allows a simultaneous analysis of all the components of FS.

The Tilburg Frailty Indicator (TFI), a tool proposed by Gobbens et $\mathrm{al}^{10}$ is based on the concept of the frailty model. ${ }^{11}$
The tool is simple for a patient and characterized good psychometric properties when studied in a Polish population. ${ }^{12}$

Functional status refers to the ability to perform activities necessary or desirable in daily life. Disability is a well-known major adverse outcome of physical frailty. ${ }^{13,14}$ Therefore, we measured the Katz Index of Independence in Activities of Daily Living (ADLs), ${ }^{15}$ which include bathing, dressing, toileting, maintaining continence, grooming, feeding, transport, and the Lawton Instrumental Activities of Daily Living (IADLs) Scale. IADLs refer to the ability to maintain an independent household, including shopping for groceries, driving or using public transportation, using the telephone, performing housework, doing home repair, preparing meals, doing laundry, taking medication, and handling finances. ${ }^{16}$

Anxiety and depression are common in older people, and also may predispose them to frailty. Previous studies have reported on cross-sectional association and poor cognition, and it has been suggested that frailty might be an indicator of future cognitive impairment. Cognitive impairment is an independent marker of functional decline and mortality. Cognitive impairment is also responsible for loss of independence, affecting individuals and families and having an impact on the health care system. Some researchers have suggested that cognitive function is a predictor of becoming frail. ${ }^{17-20}$

The latest definitions of FS adopt a multidimensional concept, where FS is described as a dynamic condition depending on a number of factors, including physical, mental, and social ones, that interact and distort the physiological balance. ${ }^{21-23}$ Therefore, the researchers need to select the appropriate definition as well as tools to study FS. ${ }^{24}$

The purpose of this study was to evaluate the correlation of the FS test scale - the TFI and its domains (mental and physical) - with other research tools, including the MiniMental State Examination (MMSE), ADL, IADL, and the Hospital Anxiety and Depression Scale (HADS), commonly used for comprehensive geriatric assessment (CGA) in patients with ACS.

\section{Methods}

\section{Study population}

The study covered 135 people, including 53 (39.3\%) women and $82(60.7 \%)$ men. The study was carried out in the cardiology ward at T Marciniak Lower Silesian Specialist Hospital in Wroclaw, Poland. Data was collected from January 2014 to August 2014. Patients were admitted with ACS. ST segment elevation myocardial infarction (STEMI) was defined as the presence of: 1) typical chest pain lasting $>30$ minutes; 2) ST segment elevation $\geq 2 \mathrm{~mm}$ 
in contiguous chest leads and/or ST segment elevation at $\geq 1 \mathrm{~mm}$ in $\geq 2$ standard leads, or new left bundle branch block; and 3) positive cardiac necrosis markers. NSTEMI was defined as the presence of: 1) typical chest pain; 2) absence of ST segment elevation; and 3) positive cardiac necrosis markers. Only the patients who underwent percutaneous coronary intervention (PCI) were included in the analysis. Inclusion criteria were age $\geq 65$ years and written informed consent for participation in the study. The assessment was made in hemodynamically stable patients. Patients admitted with severe disturbances, such as cardiogenic shock or pulmonary edema, and patients with chronic obstructive pulmonary disease, stroke, cancer, and mental disorders, as well as patients addicted to alcohol and other psychoactive substances, were excluded from the study.

This study was approved by the Bioethical Commission of the Medical University of Wroclaw (number KB-521/2014).

\section{Measures}

\section{Description of the TFI}

The TFI consists of two different parts. One part addresses the sociodemographic characteristics of a participant (sex, age, marital status, country of origin, educational level, and monthly income) and potential determinants of frailty. The second part addresses the components of frailty. Part two of the TFI comprises 15 self-reported questions, divided into three domains. The physical domain ( $0-8$ points) consists of eight questions related to physical health, unexplained weight loss, difficulty in walking, balance problems, hearing problems, vision problems, strength in hands, and physical tiredness. The psychological domain ( $0-4$ points) comprises four items related to cognition, depressive symptoms, anxiety, and coping. The social domain (0-3 points) comprises three questions related to living alone, social relations, and social support. Eleven items from part two of the TFI have two response categories ("yes" and "no"), while the other items have three ("yes", "no," and "sometimes"). "Yes" or "sometimes" responses are scored 1 point each, while "no" responses are scored 0 . The instrument's total score may range from 0 to 15: the higher the score, the higher one's frailty. Frailty is diagnosed when the total TFI score is $>5 .^{10-12}$

\section{Description of the MMSE}

The MMSE is a very brief, easily administered mental status examination that has proved to be a highly reliable and valid instrument for detecting and tracking the progression of the cognitive impairment associated with neurodegenerative diseases. Consequently, the MMSE is the most widely used mental status examination in the world. ${ }^{25,26}$ The maximum MMSE score is 30 . The cut-off scores of 24-25 provide a reliable diagnosis of dementia with high sensitivity, specificity, and diagnostic values..$^{25,26}$

\section{Description of the HADS}

The HADS is a screening tool for anxiety and depression in nonpsychiatric clinical populations. It is thought to tap into the construct of affect. The scale consists of 14 items (seven each for anxiety and depression). Responses are based on the relative frequency of symptoms over the preceding week. Possible scores range from 0 to 21 for each subscale. An analysis of scores on the two subscales supported the differentiation of each mood state into four ranges: "mild cases" (scores 8-10), "moderate cases" (scores 11-15), and "severe cases" (scores 16 or higher). ${ }^{27,28}$

\section{Description of the ADLs}

The index of ADLs counts the number of ADLs for which a person needs help, and is the classic measure of the severity of the need for personal assistance services and other longterm services and support. Clients are scored with yes/no for independence in each of the six functions. A score of 6 indicates full function; 4 indicates moderate impairment; and 2 or less indicates severe functional impairment. ${ }^{14}$

\section{Description of IADLs}

This index measures a patient's ability to maintain an independent household, eg, shopping for groceries, driving or using public transportation, using the telephone, performing housework, doing home repair, preparing meals, doing laundry, taking medication, and handling finances. ${ }^{16}$

\section{Analytic strategy}

Correct distribution of the continuous variables was verified with the Shapiro-Wilk test, and their statistical characteristics are presented as arithmetic means, standard deviations, medians, interquartile range (IQRs), and ranges. The power and direction of the relationship between the values of the TFI and other scales were evaluated based on the value of the Pearson's coefficient of linear correlation $(r)$. The Student's $t$-test was used for nonrelated variables to compare the results of each scale in the subgroups of patients with TFI $\geq 5$ and $<5$. The compliance of distribution of each scale value was evaluated based on the value of coefficient $\Phi$ and the result of Pearson's chi-square test. The calculations were 
made with the use of Statistica 10 software (StatSoft, Tulsa, OK, USA); the assumed level of significance was $P \leq 0.05$ for all tests.

\section{Results}

The study covered a group of 135 people, including $53(39.3 \%)$ women and $82(60.7 \%)$ men. The mean age of the studied population was 69.8 \pm 11.4 years (median: 68, IQR: 60-79, range: 50-92). The sociodemographic data are given in Table 1.

\section{Values of TFI}

The mean value of the TFI in the studied group amounted to 7.13 \pm 2.81 (median: 7, IQR: 5-9, range: 0-14). The studied population included $105(77.8 \%)$ people with a value of TFI $\geq 5$ and $30(22.2 \%)$ non-frail people with a TFI value $<5$.

\section{Relationship between the TFI and values of the ADL scale}

The mean value of the ADL scale in the studied group

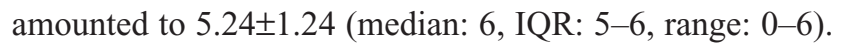
The studied population included 25 (18.5\%) people with values of the ADL scale $<5$ and $110(81.5 \%)$ with values of the ADL scale $\geq 5$. Significant reverse correlation between the values of the ADL scale and the values of the TFI ( $r=-0.428, P<0.001$ ) (Figure $1 \mathrm{~A})$ and its physical dimension ( $r=-0.461, P<0.001)$ (Figure 2A) were demonstrated. Patients with a TFI $\geq 5$ demonstrated considerably lower values of the ADL scale ( $P=0.002)$ (Figure $3 \mathrm{~A})$. A significant relationship between the coexistence of the value of the TFI $\geq 5$ and the value of the ADL scale $<5(\Phi=0.209, P=0.015)$ (Table 1) was demonstrated.

\section{Relationship of the TFI with the values of the IADL scale}

The mean value of the IADL scale in the studied population amounted to $21.21 \pm 4.08$ (median: 24 , IQR: 20-24, range: $8-24)$. The studied population included only five $(3.7 \%)$ people with the value of the IADL scale $<12$ and as many as $130(96.3 \%)$ people with the IADL scale value $\geq 12$. Significant reverse correlations between the values of the IADL scale and the TFI ( $r=-0.462, P<0.001)$ (Figure 1B) and its physical dimension $(r=-0.462, P<0.001)$ (Figure $2 \mathrm{~B}$ ) were demonstrated. Patients with a TFI $\geq 5$ revealed considerably lower values of the IADL scale ( $P=0.001)$ (Figure 3B). However, no significant relationship between the coexistence of the TFI value $\geq 5$ and the value of the IADL scale $<12(\Phi=0.010, P=0.903)$ (Table 1) was discovered.
Table I Sociodemographic and clinical characteristics of the studied population

\begin{tabular}{|c|c|}
\hline Variable & Whole group $\mathbf{N}=135$ \\
\hline \multicolumn{2}{|l|}{ Sex } \\
\hline Men, n (\%) & $82(60.7)$ \\
\hline Women, n (\%) & $53(39.3)$ \\
\hline \multicolumn{2}{|l|}{ Age (years) } \\
\hline$M \pm S D$ & $69.8 \pm 11.4$ \\
\hline $\operatorname{Me}\left(Q_{1} ; Q_{3}\right)$ & $68(60 ; 79)$ \\
\hline Min-max & $50-92$ \\
\hline \multicolumn{2}{|l|}{ Age groups (years) } \\
\hline I: 50-59, n (\%) & $30(22.2)$ \\
\hline II: $60-74, \mathrm{n}(\%)$ & $52(38.5)$ \\
\hline III: 75-89, n (\%) & $49(36.3)$ \\
\hline IV: 90-92, n (\%) & $4(3.0)$ \\
\hline \multicolumn{2}{|l|}{ BMI $\left(\mathrm{kg} / \mathrm{m}^{2}\right)$} \\
\hline$M \pm S D$ & $26.9 \pm 4.6$ \\
\hline $\operatorname{Me}\left(Q_{1} ; Q_{3}\right)$ & $26.4(23.4 ; 30.1)$ \\
\hline Min-max & $|6.4-4| .1$ \\
\hline \multicolumn{2}{|l|}{ Marital status } \\
\hline Married, n (\%) & $76(56.3)$ \\
\hline Single, n (\%) & $59(43.7)$ \\
\hline \multicolumn{2}{|l|}{ Education } \\
\hline Primary, n (\%) & $23(17.0)$ \\
\hline Vocational, n (\%) & $50(37.1)$ \\
\hline Secondary, n (\%) & $54(40.0)$ \\
\hline Higher, n (\%) & $8(5.9)$ \\
\hline \multicolumn{2}{|l|}{ Place of residence } \\
\hline City/town, n (\%) & I I4 (84.4) \\
\hline Village/country, n (\%) & $21(15.6)$ \\
\hline \multicolumn{2}{|l|}{ ACS severity } \\
\hline STEMI, n (\%) & $61(45.2)$ \\
\hline NSTEMI, n (\%) & $64(47.4)$ \\
\hline UA, n (\%) & $10(7.4)$ \\
\hline \multicolumn{2}{|l|}{ Therapeutic interventions } \\
\hline $\mathrm{PCl}, \mathrm{n}(\%)$ & $100(74.1)$ \\
\hline Qualification for CABG, n (\%) & $16(11.8)$ \\
\hline Pharmacological treatment, n (\%) & $19(14.1)$ \\
\hline \multicolumn{2}{|l|}{ Concomitant diseases $^{\mathrm{a}}$} \\
\hline Arterial hypertension, $\mathrm{n}(\%)$ & $106(78.5)$ \\
\hline Renal malfunction, $\mathrm{n}(\%)$ & $14(10.4)$ \\
\hline Diabetes, n (\%) & $30(22.2)$ \\
\hline
\end{tabular}

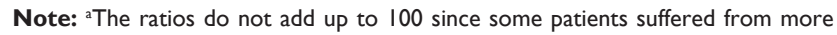
than one disease.

Abbreviations: ACS, acute coronary syndrome; BMI, body mass index; CABG, coronary artery bypass graft; $M$, mean; max, maximum; min, minimum; Me, Median; (QI;Q3), (first quartile; third quartile); NSTEMI, non-ST segment elevation myocardial infarction; $\mathrm{PCl}$, percutaneous coronary intervention; SD, standard deviation; STEMI, ST segment elevation myocardial infarction; UA, unstable angina.

\section{Relationship of the TFI with the values of the HADS}

The mean value of the HADS in the studied group amounted to $13.25 \pm 9.89$ (median: 10, IQR: 23-29, range: 0-43). The studied population included $91(67.4 \%)$ people with a value of the HADS $>7$ and $44(32.6 \%)$ people with a value of the HADS $\leq 7$. Significant positive correlations between the values of the HADS and the value of the TFI $(r=0.602$, 
A

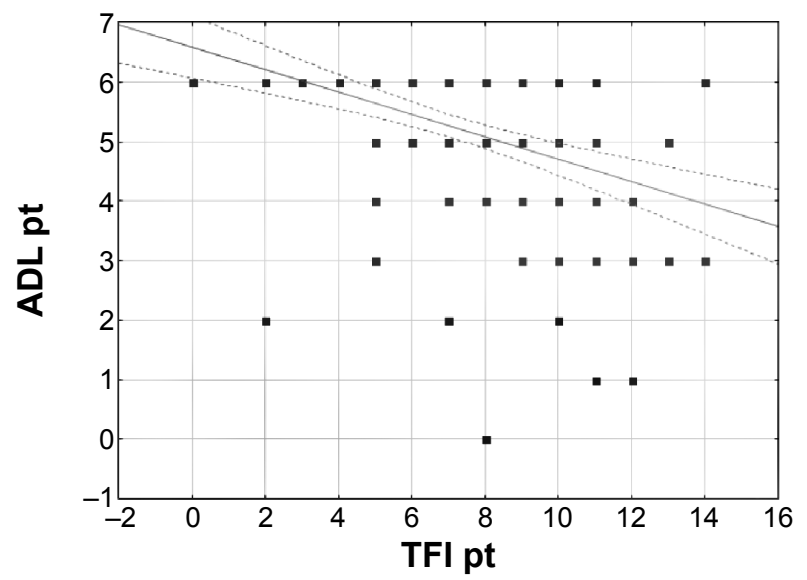

C

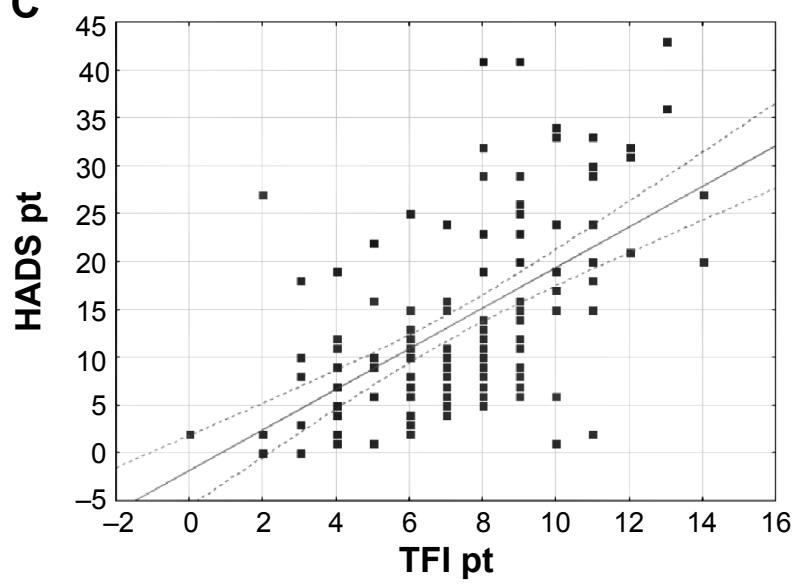

B

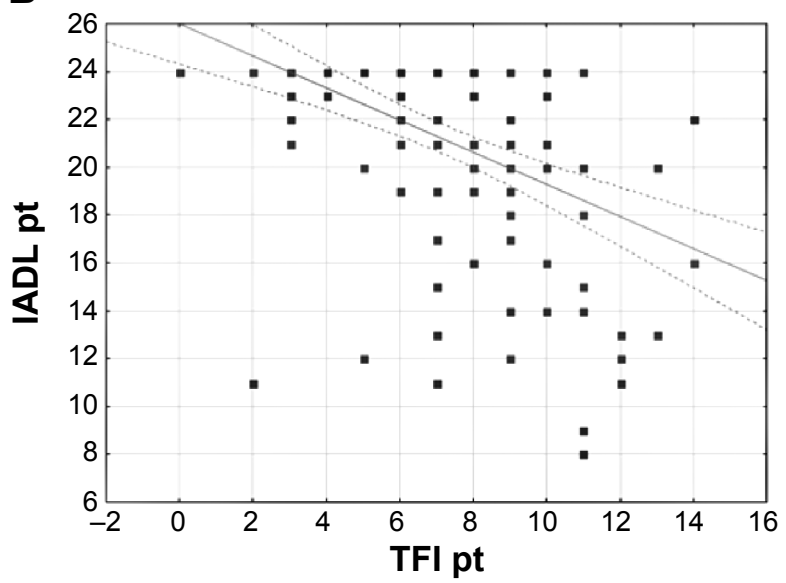

D

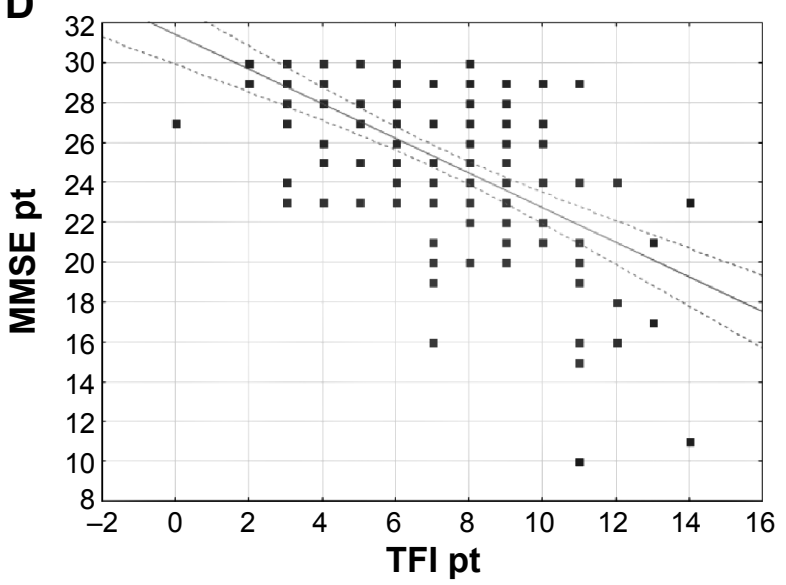

Figure I Relationships between the TFI values and values of the ADL (A), IADL (B), HADS (C), and MMSE (D) scales.

Abbreviations: ADL, Katz Index of Independence in Activities of Daily Living; HADS, Hospital Anxiety and Depression Scale; IADL, The Lawton Instrumental Activities of Daily Living Scale; MMSE, Mini-Mental State Examination; TFI, Tilburg Frailty Indicator.

$P<0.001)$ (Figure 1C) and its mental dimensions $(r=0.586$, $P<0.001$ ) (Figure $2 \mathrm{C}$ ) were demonstrated. Patients with a TFI $\geq 5$ revealed considerably higher values of the HADS $(P<0.001)$ (Figure 3C). A significant relationship between the coexistence of the value of the TFI $\geq 5$ and the value of the HADS $>7(\Phi=0.389, P=0.001)$ (Table 1) was also demonstrated.

\section{Relationship of the TFI with the values of the MMSE scale}

The mean value of the MMSE scale in the studied group amounted to $25.22 \pm 4.05$ (median: 26, IQR: 23-29, range: 10-30). The studied population included 40 (29.6\%) people with the value of the MMSE scale $<24$ and 95 (70.4\%) people with the value of the MMSE scale $\geq 24$. Significant reverse correlations between the values of the MMSE scale and the value of the TFI $(r=-0.603, P<0.001)$ (Figure 1D) and its mental dimension $(r=-0.413, P<0.001)$ (Figure 2D) were demonstrated. Patients with the TFI $\geq 5$ revealed considerably lower values of the MMSE scale $(P<0.001)$ (Figure 3D). A significant relationship between the coexistence of the value of the TFI $\geq 5$ and the value of the MMSE scale $<24$ $(\Phi=0.269, P=0.002)$ (Table 2) was also demonstrated.

\section{Multidimensional analysis}

A multiple regression analysis revealed that the parameters with a significant, independent effect on the TFI level included the values of the HADS and MMSE scale. In turn, in the multidimensional model of logistic regression, the only independent predicator of the TFI $\geq 5$ turned out to be the occurrence of the HADS value $>7$ (odds ratio $[\mathrm{OR}]=4.84,95 \%$ confidence interval [CI]: 1.91-12.22, $P=0.001)$. No statistically significant relationship between the coexistence of a TFI $\geq 5$ and a value of the ADL scale $<5(\mathrm{OR}=3.74,95 \% \mathrm{CI}$ : $0.42-33.42, P=0.234)$ and MMSE scale $<24(\mathrm{OR}=3.57$, $95 \%$ CI: $0.72-17.66, P=0.116)$ was demonstrated. 
A

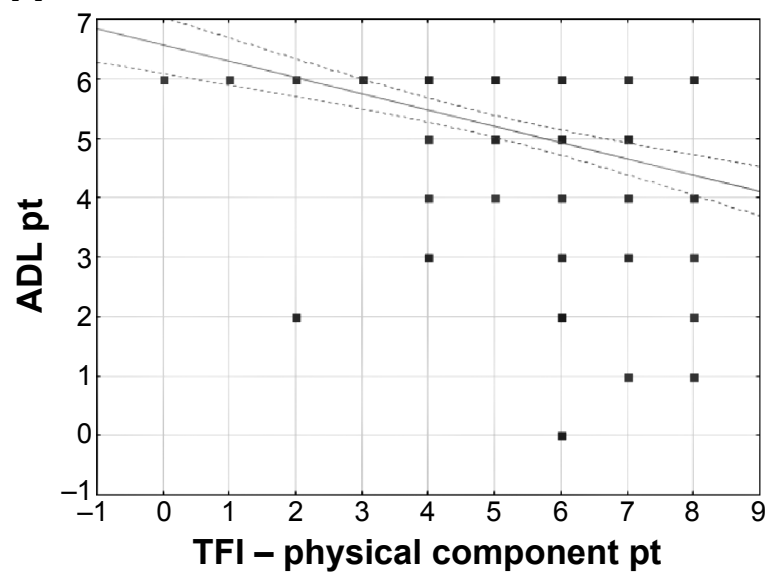

C

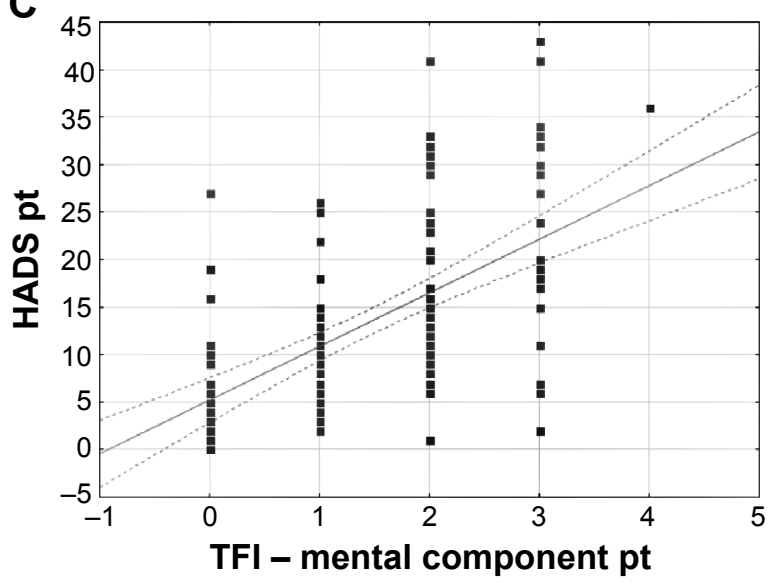

B

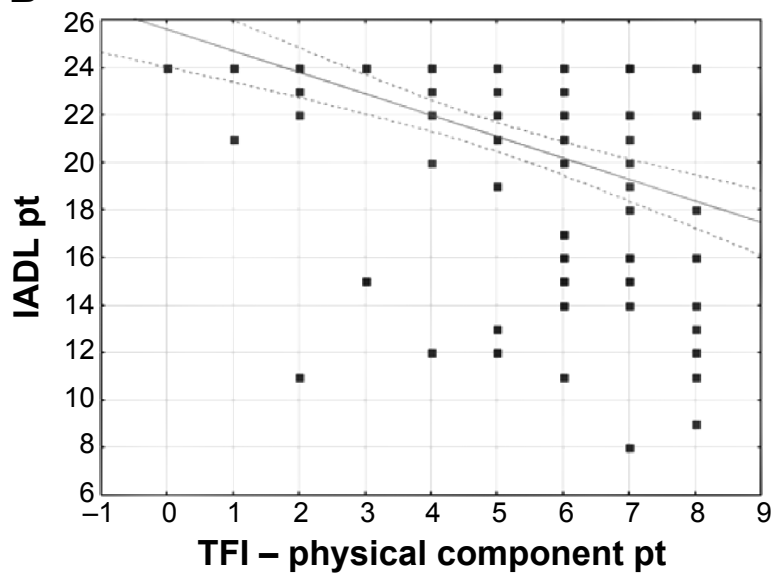

D

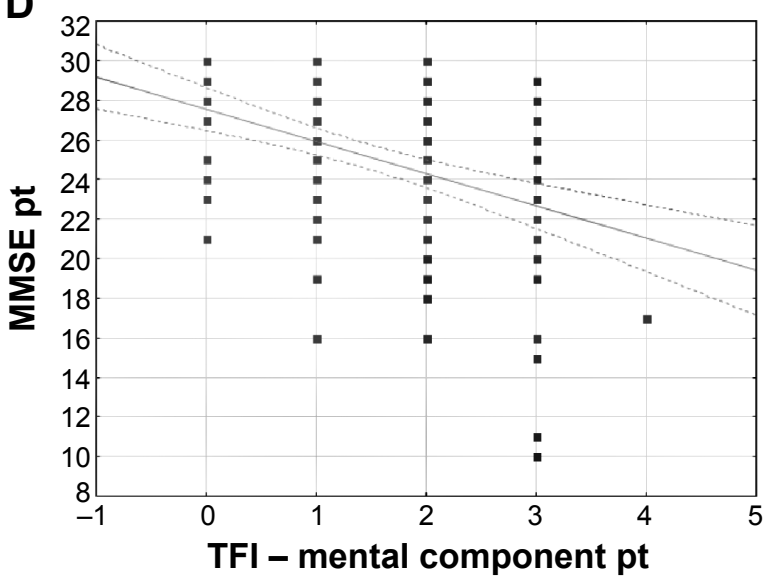

Figure 2 Relationships between the values of the physical dimension of the TFI and the values of the ADL (A) and IADL (B) scales, and between the values of the mental dimension of the TFI and the values of the HADS (C) and MMSE (D) scales.

Abbreviations: ADL, Katz Index of Independence in Activities of Daily Living; HADS, Hospital Anxiety and Depression Scale; IADL, The Lawton Instrumental Activities of Daily Living Scale; MMSE, Mini-Mental State Examination; TFI, Tilburg Frailty Indicator.

\section{Discussion}

Neither a unanimous operating definition of FS nor uniform diagnostic criteria of the syndrome have been developed so far. ${ }^{31} \mathrm{FS}$ is a consequence of reduced physiological reserves of many body organs. ${ }^{29-31}$ Moreover, FS results in poorer functioning in biopsychosocial areas, translating into a poorer response to both physical and mental stressors. Factors involved in the etiopathogenesis of FS include biological (inflammatory, hormones), clinical (sarcopenia, osteoporosis, and other concomitant diseases), and social (social isolation, poor financial condition). ${ }^{32}$ The occurrence of FS leads to poorer functioning in the elderly in many aspects, as well as to an increased risk of disease, hospitalization, institutionalization, or even death; the problems gain particular significance in the case of patients suffering from chronic diseases. ${ }^{8}$

There are a number of instruments (clinical and instrumental tests, self-return questionnaires, etc) that allow the assessment of the components of FS from the physical domain (physical activity, nutrition, handgrip strength, risk of falling down) $)^{15,16,29,31,32}$ mental domain (cognitive functions, mood, depression) ${ }^{25,26,29,30}$ and social domain (social isolation, social support). ${ }^{10,11}$ Furthermore, the literature mentions research tools that can be used for comprehensive diagnostics of FS: 1) the Cardiovascular Health Study (CHS) Scale; 2) the Edmonton Frail Scale (EFS); 3) the TFI; 4) the Canadian Study on Health and Aging (CSHA) Frailty Index; 5) the FRAIL scale; and 6) the Groningen Frailty Indicator (GFI). . $^{8,11,30,31,33}$

The purpose of the present study was to establish whether the TFI correlates with single tools (ADL, IADL, MMSE, and HADS) used for assessing various aspects of elderly age in CGA, and to compare the predictive values of single-measure instruments with the TFI in the ACS population. A similar study was performed by Gobbens et $\mathrm{al}^{34}$ where the authors assessed the predictive validity of the eight individual self-reported components of the physical frailty subscale of the TFI for the total disability, ADL disability, and IADL disability in older people. Low 
A

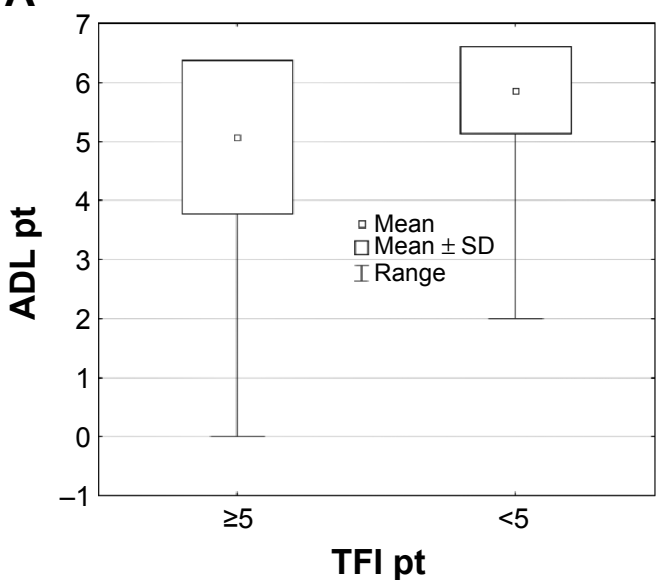

C

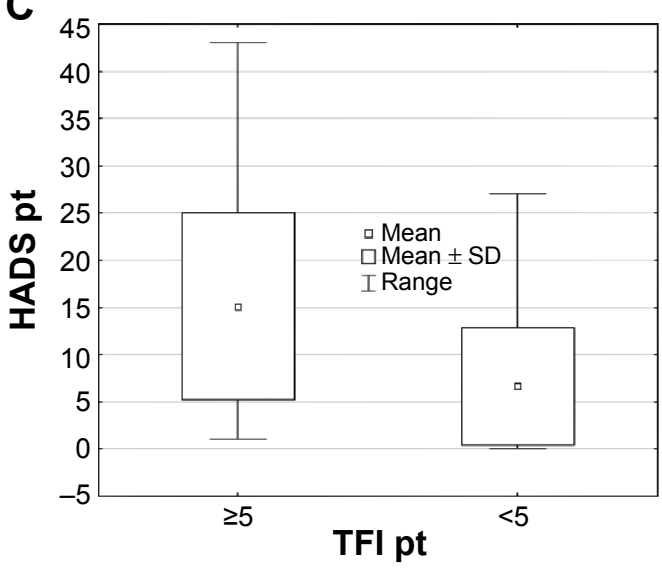

B

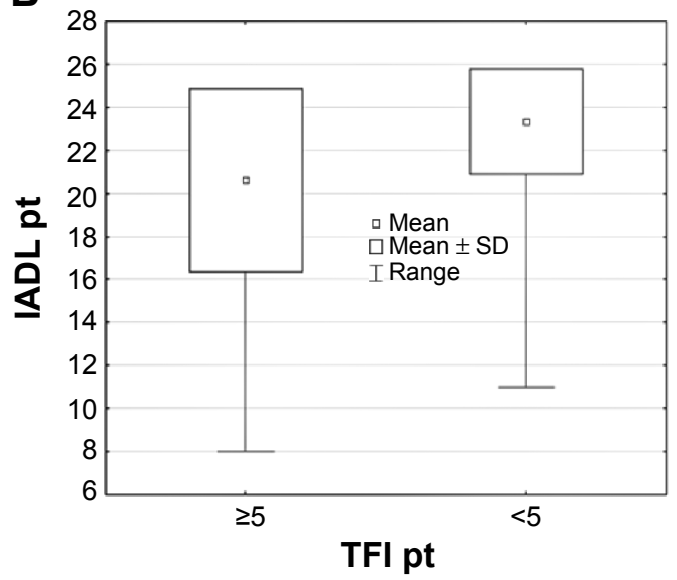

D

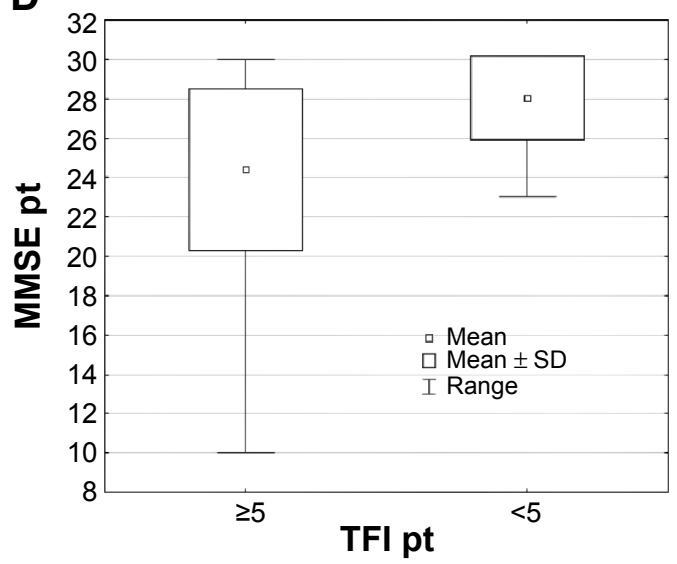

Figure 3 Statistical characteristics of the values of the ADL (A), IADL (B), HADS (C), and MMSE (D) scales in the subgroups of patients with the TFI values $\geq 5$ and $<5$. Abbreviations: ADL, Katz Index of Independence in Activities of Daily Living; HADS, Hospital Anxiety and Depression Scale; IADL, The Lawton Instrumental Activities of Daily Living Scale; MMSE, Mini-Mental State Examination; SD, standard deviation; TFI, Tilburg Frailty Indicator.

physical activity was associated with a greater total and ADL disability. Slowness was associated with a higher total and IADL disability, and weakness with a lower IADL disability. ${ }^{34}$ In our study, a significant relationship between the coexistence of a TFI value $\geq 5$ and an ADL scale value $<5$

Table 2 Distribution of the number and percentage of patients with different values of the ADL, HADS, and MMSE scales in the subgroups of patients with the TFI values $\geq 5$ and $<5$

\begin{tabular}{lllll}
\hline Scale & $\begin{array}{l}\text { TFI } \geq \mathbf{5}, \mathbf{n}(\%) \\
(\mathbf{n}=\mathbf{1 0 5})\end{array}$ & $\begin{array}{l}\text { TFI }<\mathbf{5}, \mathbf{n}(\%) \\
(\mathbf{n}=\mathbf{3 0})\end{array}$ & $\mathbf{\Phi}$ & P-value \\
\hline $\mathrm{ADL}<5$ & $24(22.9)$ & $\mathrm{I}(3.3)$ & 0.209 & 0.015 \\
$\mathrm{ADL} \geq 5$ & $8 \mathrm{I}(77 . \mathrm{I})$ & $29(96.7)$ & & \\
$\mathrm{IADL}<12$ & $4(3.8)$ & $\mathrm{I}(3.3)$ & 0.010 & 0.903 \\
$\mathrm{IADL} \geq 12$ & $\mathrm{I} 1 \mathrm{I}(96.2)$ & $29(96.7)$ & & \\
$\mathrm{HADS}>7$ & $8 \mathrm{I}(77.1)$ & $10(33.3)$ & 0.389 & $<0.00 \mathrm{I}$ \\
$\mathrm{HADS} \leq 7$ & $24(22.9)$ & $20(66.7)$ & & \\
MMSE $<24$ & $38(36.2)$ & $2(6.7)$ & 0.269 & 0.002 \\
MMSE $\geq 24$ & $67(63.8)$ & $28(93.3)$ & & \\
\hline
\end{tabular}

Abbreviations: ADL, Katz Index of Independence in Activities of Daily Living; HADS, Hospital Anxiety and Depression Scale; IADL, The Lawton Instrumental Activities of Daily Living Scale; MMSE, Mini-Mental State Examination; TFI, Tilburg Frailty Indicator. was demonstrated, which means, similarly to Gobbens and van Assen's research, that physical frailty measured by the TFI is comparable with lower ADL scores. ${ }^{34}$ The same relationship was observed between the coexistence of a TFI value $\geq 5$ and the HADS and MMSE scale values. Additionally, significant positive correlations between the HADS values had significant positive correlations with the TFI and its mental dimension, were discovered. Patients with a TFI value $\geq 5$ demonstrated significantly higher values of the HADS. Therefore, it can be concluded that frailty causes deterioration of the cognitive functions and contributes to the occurrence of fear and depression as measured in the mental dimension of the TFI scale. Cardiovascular disease is a leading cause of morbidity and mortality in older individuals, and managing elderly patients with ACS can be challenging. The presence of FS in the elderly population can be meaningful for taking decisions as to therapy and for stratification of cardiovascular risk. The majority of scales used for risk assessment are based on chronological age. However, chronological age does not always reflect the biological age of the patient and 
its use may lead to inaccurate estimation of the patient's risk. Nowadays, the significance of biological age for making medical decisions is emphasized. This can be identified using FS diagnostics, which are the exponents of advanced age. Therefore, the use of the TFI, which is a multidimensional tool, can be helpful for assessing frailty at the bedside with ACS patients, and may change our approach towards those patients because they may need special attention. As we said previously, recent study demonstrated that over $50 \%$ of elderly patients with cardiovascular diseases are frail, which makes FS a major problem as frailty is associated with increased mortality. ${ }^{8}$

In the literature, we found only one study in which frailty was measured as an outcome in elderly patients with ACS. The study was performed by Graham et al and the authors administered the EFS to ACS patients to assess frailty. They concluded that the EFS may also be used as a simple frailty assessment tool administered by non-geriatricians to a group of older patients with ACS. ${ }^{35}$

The TFI is not superior to other frailty instruments, but it might be a useful tool for assessing frailty and helping with the geriatric assessment.

\section{Study limitations}

We are well aware of potential limitations of this study. The most important of these stems from the fact that our study sample size was relatively low, and the sample was recruited at a single center.

\section{Conclusion}

The results of the TFI comply with the results of other scales (ADL, IADL, MMSE, and HADS), which confirms the credibility of the Polish adaptation of the tool. Stronger correlations concerned mental components, while the mental scales turned out to be independently related to TFI in a multidimensional analysis. To conclude, the assessment of frailty with TFI can be very useful for CGA.

\section{Disclosure}

The authors report no conflicts of interest in this work.

\section{References}

1. European Commission. 2009 Ageing Report: Economic and Budgetary Projections for the EU-27 Member States (2008-2060). Luxembourg: Office for Official Publications of the European Communities; 2009. Available from: http://ec.europa.eu/economy_finance/publications/ publication14992_en.pdf. Accessed October 21, 2012.

2. Ekerstad N, Swahn E, Janzon M, et al. Frailty is independently associated with short-term outcomes for elderly patients with non-ST-segment elevation myocardial infarction. Circulation. 2011;124:2397-2404.
3. Hogan DB, MacKnight C, Bergman H; Steering Committee, Canadian Initiative on Frailty and Aging. Model, definitions, and criteria of frailty. Aging Clin Exp Res. 2003;15:1-29.

4. Życzkowska J, Grądalski T. Zespół słabości (frailty) - co powinien wiedzieć o nim onkolog? [Frailty - an overview for oncologists]. Onkologia w Praktyce Klinicznej. 2010;6:79-84. Polish.

5. Alexander KP, Newby LK, Cannon CP, et al; American Heart Association Council on Clinical Cardiology; Society of Geriatric Cardiology. Acute coronary care in the elderly, part I: non-ST-segment-elevation acute coronary syndromes: a scientific statement for healthcare professionals from the American Heart Association Council on Clinical Cardiology: in collaboration with the Society of Geriatric Cardiology. Circulation. 2007;115:2549-2569.

6. Avezum A, Makdisse M, Spencer F, et al; GRACE Investigators. Impact of age on management and outcome of acute coronary syndrome: observations from the Global Registry of Acute Coronary Events (GRACE). Am Heart J. 2005;149:67-73.

7. Topol EJ, Califf RM, Van de Werf F, et al. Perspectives on large-scale cardiovascular clinical trials for the new millennium. The Virtual Coordinating Center for Global Collaborative Cardiovascular Research (VIGOUR) Group. Circulation. 1997;95:1072-1082.

8. Afilalo J. Frailty in patients with cardiovascular disease: why, when, and how to measure. Curr Cardiovasc Risk Rep. 2011;5: 467-472.

9. Topinková E. Aging, disability and frailty. Ann Nutr Metab. 2008;52 Suppl 1:6-11.

10. Gobbens RJ, van Assen MA, Luijkx KG, Schols JM. The predictive validity of the Tilburg Frailty Indicator: disability, health care utilization, and quality of life in a population at risk. Gerontologist. 2012;52:619-631.

11. Gobbens RJ, van Assen MA, Luijkx KG, Wijnen-Sponselee MT, Schols JM. The Tilburg Frailty Indicator: psychometric properties. J Am Med Dir Assoc. 2010;11:344-355.

12. Uchmanowicz I, Jankowska-Polańska B, Łoboz-Rudnicka M, Manulik S, Łoboz-Grudzień K, Gobbens RJ. Cross-cultural adaptation and reliability testing of the Tilburg Frailty Indicator for optimizing care of Polish patients with frailty syndrome. Clin Interv Aging. 2014; 9:997-1001.

13. Cesari M, Penninx BW, Pahor M, et al. Inflammatory markers and physical performance in older persons: the InCHIANTI study. $J$ Gerontol $A$ Biol Sci Med Sci. 2004;59:242-248.

14. American College of Sports Medicine, Chodzko-Zajko WJ, Proctor DN, et al. American College of Sports Medicine position stand. Exercise and physical activity for older adults. Med Sci Sports Exerc. 2009;41:1510-1530.

15. Katz S, Ford AB, Moskowitz RW, Jackson BA, Jaffe MW. Studies of illness in the aged. The Index of ADL: a standardized measure of biological and psychosocial function. JAMA. 1963;185:914-919.

16. Barberger-Gateau P, Dartigues JF, Letenneur L. Four Instrumental Activities of Daily Living Score as a predictor of one-year incident dementia. Age Ageing. 1993;22:457-463.

17. Ní Mhaoláin AM, Fan CW, Romero-Ortuno R, et al. Frailty, depression, and anxiety in later life. Int Psychogeriatr. 2012;24(8):1265-1274.

18. Dodson JA, Chaudhry SI. Geriatric conditions in heart failure. Curr Cardiovasc Risk Rep. 2012;6:404-410.

19. Lupón J, González B, Santaeugenia S, et al. Prognostic implication of frailty and depressive symptoms in an outpatient population with heart failure. Rev Esp Cardiol. 2008;61:835-842. English, Spanish.

20. Wells JL, Seabrook JA, Stolee P, Borrie MJ, Knoefel F. State of the art in geriatric rehabilitation. Part I: review of frailty and comprehensive geriatric assessment. Arch Phys Med Rehabil. 2003;84:890-897.

21. Woo J, Goggins W, Sham A, Ho SC. Social determinants of frailty. Gerontology. 2005;51(6):402-408.

22. Ostir GV, Ottenbacher KJ, Markides KS. Onset of frailty in older adults and the protective role of positive affect. Psychol Aging. 2004; 19(3):402-408. 
23. Gobbens RJ, Luijkx KG, Wijnen-Sponselee MT, Schols JM. In search of an integral conceptual definition of frailty: opinions of experts. $J \mathrm{Am}$ Med Dir Assoc. 2010;11(5):338-343.

24. Fisher AL. Just what defines frailty? J Am Geriatr Soc. 2005; 53(12):2229-2230.

25. Folstein MF, Folstein SE, Fanjiang G. Mini-Mental State Examination: Clinical Guide. Odessa, FL: Psychological Assessment Resources; 2001.

26. Folstein MF, Folstein SE, McHugh PR. "Mini-mental state". A practical method for grading the cognitive state of patients for the clinician. J Psychiatr Res. 1975;12:189-198.

27. Zigmond AS, Snaith RP. The hospital anxiety and depression scale. Acta Psychiatr Scand. 1983;67:361-370.

28. Woolrich RA, Kennedy P, Tasiemski T. A preliminary psychometric evaluation of the Hospital Anxiety and Depression Scale (HADS) in 963 people living with a spinal cord injury. Psychol Health Med. 2006;11:80-90.

29. Aminzadeh F, Dalziel W, Molnar FJ. Targeting frail older adults for outpatient comprehensive geriatric assessment and management services: an overview of concepts and criteria. Rev Clin Gerontol. 2002; 12:82-92.
30. Campbell AJ, Buchner DM. Unstable disability and the fluctuations of frailty. Age Ageing. 1997;26:315-318.

31. Rockwood K. What would make a definition of frailty successful? Age Ageing. 2005;34:432-434.

32. Ferrucci L, Guralnik JM, Studenski S, Fried LP, Cutler GB Jr, Walston JD; Interventions on Frailty Working Group. Designing randomized, controlled trials aimed at preventing or delaying functional decline and disability in frail, older persons: a consensus report. $J \mathrm{Am}$ Geriatr Soc. 2004;52:625-634.

33. Fried LP, Tangen CM, Walston J, et al; Cardiovascular Health Study Collaborative Research Group. Frailty in older adults: evidence for a phenotype. J Gerontol A Biol Sci Med Sci. 2001;56:M146-M156.

34. Gobbens RJ, van Assen MA. The Prediction of ADL and IADL Disability Using Six Physical Indicators of Frailty: A Longitudinal Study in the Netherlands. Curr Gerontol Geriatr Res. 2014; 2014:358137.

35. Graham MM, Galbraith DP, O’Neill D, Rolfson DB, Dando C, Norris CM. Frailty and outcome in elderly patients with acute coronary syndrome. Can J Cardiol. 2013;29:1610-1615.
Clinical Interventions in Aging

\section{Publish your work in this journal}

Clinical Interventions in Aging is an international, peer-reviewed journal focusing on evidence-based reports on the value or lack thereof of treatments intended to prevent or delay the onset of maladaptive correlates of aging in human beings. This journal is indexed on PubMed Central, MedLine,

\section{Dovepress}

CAS, Scopus and the Elsevier Bibliographic databases. The manuscript management system is completely online and includes a very quick and fair peer-review system, which is all easy to use. Visit http://www.dovepress. com/testimonials.php to read real quotes from published authors. 